Journal of Speech Sciences 3(1):169:180.2013

Available at: hhtp://www.journalofspeechsciences.org

\title{
Doubling of the number of hands as a resource for the expression of meaning intensification in Brazilian Sign Language (Libras)
}

XAVIER, A. N. ${ }^{1}$

State University of Campinas (Unicamp), Campinas, Brazil.

\begin{abstract}
Signs, the lexical items of signed languages, can be articulatorily characterized as one or two-handed (Klima and Bellugi, 1979). It has been observed in some signed languages that some one-handed signs can undergo doubling of manual articulator to express meaning intensification (Johnston and Schembri, 1999; Hendriks, 2007). This work reports the results of an experiment designed and carried out (1) to elicit intensified forms of some signs of Brazilian Sign Language (Libras) and (2) to check the extent to which the doubling of the number of hands in signs typically produced with only one hand is employed as a resource for the intensification of their meaning. Even though the analysis of the data obtained revealed that subjects were consistent in changing their facial and body expressions as well as the aspects of their hands' movement when producing the intensified forms of a sign, the same does not hold true about the doubling of the number of hands in one-handed signs for the same purpose. Out of 12 deaf subjects, users of Libras, only 6 produced a few one-handed sign with two hands when intensifying their meaning and mostly not for the same sign.
\end{abstract}

Key words: sign language; doubling; number of hands; meaning intensification.

\section{Introduction}

(1) was the first researcher to propose phonological units for the analysis of a sign language's lexical items. The units or aspects he proposed were hand configuration, location and movement. Later, (2) included among those aspects palm orientation, since, as (1), he found pairs of signs in American Sign Language (ASL) that contrasted between themselves only in terms of the direction to which the palm of the hand is oriented.

Other phonological units have been proposed by other researchers since then. Among them are contact region (the part of the hand that touches a location on the body) and hand arrangement (the number of

${ }^{1}$ Corresponding author: andre.xavier.unicamp@gmail.com 
hands with which a sign is produced) (3). These parameters were called by (3) minor parameters, because, according to the authors, there are a few number of pairs of signs in ASL whose lexical contrast is based only in one of them.

Brazilian Sign Language (henceforth Libras) has also been phonologically analyzed in terms of the parameters discussed up to now (4). Specifically in relation to the minor parameter hand arrangement, this preliminary analysis revealed that, Libras, as ASL, exhibits just a few pairs of unrelated signs contrasting only (or mainly) in terms of the number of hands with which they are articulated.

One of these few examples is the pair DIFFERENT and IT-IS-NOT (Fig. 1), which differs basically in the fact that the former is articulated with two hands, whereas the latter is realized with only one.

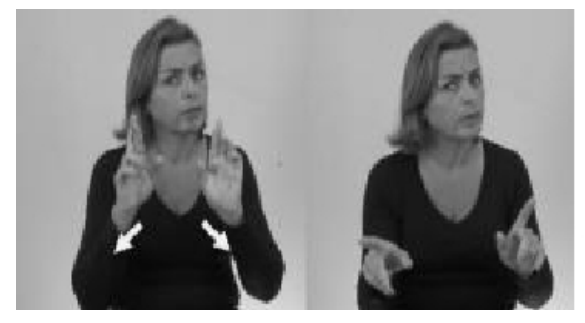

(a)

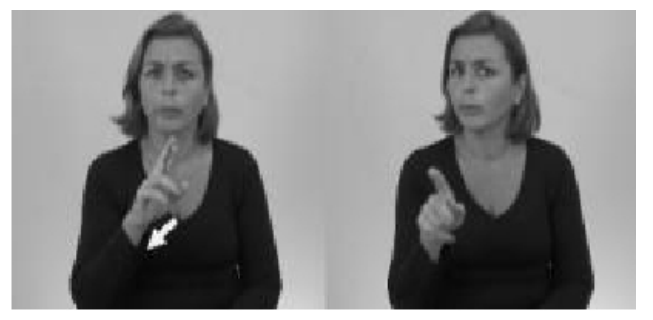

(b)

Figure 1 - DIFFERENT (a) vs IT-IS-NOT (b), a minimal pair in which the contrast is based in the number of hands

(4) also showed that there seems not to be a great difference in quantitative terms in relation to the number of one-handed versus two-handed signs in Libras. Out of 2,269 signs selected from a Libras dictionary (5), $44 \%$ of the signs are produced with one hand, whereas $56 \%$ are articulated with two hands.

In a more recent work, $(6,7)$, however, points out that some signs in Libras exhibit variation in terms of the number of hands with which they are produced. $(6,7)$ shows that some one-handed signs can sometimes be produced with two hands and that some two-handed signs can, in turn, sometimes be realized with only one hand. These phenomena are reported for ASL $(8,9,10)$ and Australian Sign Language (Auslan) (11). (11) call the former process $(2>1)$ doubling and the latter $(1>2)$ singling.

As (11), (6) also found different factors governing the alternation of the number of hands in some signs, among which are grammatical and lexical processes, as well as co-articulation (7). In this paper, I will focus on one of the factors that may make a one-handed sign be realized with two hands: the intensification of meaning.

In spontaneous signing, it is common to see one-handed signs being produced with two hands as a means to express the intensification of their meaning. This is what seems to happen in the examples below, extracted from a video available on Youtube (http://www.youtube.com/watch?v=H89DbjtrpPg). In this video a signer gives the viewers a tour in the signed language department of his university. In the segment of the video of interest here the signer tells the viewers that he has more places to show them 
and he does so by first producing the Libras sign MORE with only one hand (at 2'37' of the video), as it is usually produced. Later on, asks the viewers if they think if what he has shown is all, then, he answers his own question saying emphatically that there is still more to see, in fact, much more. This time (at 7'10"), he realizes MORE with two hands and e seems to do so for intensifying or emphasizing the meaning of the sign. This can be supported by his facial expressions, torso posture and the characteristics of his hands' movement.

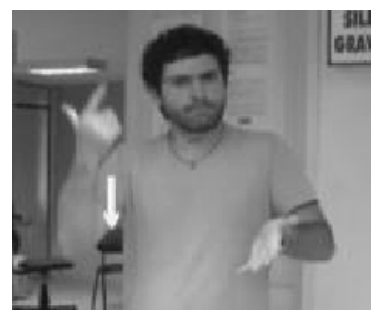

(a)

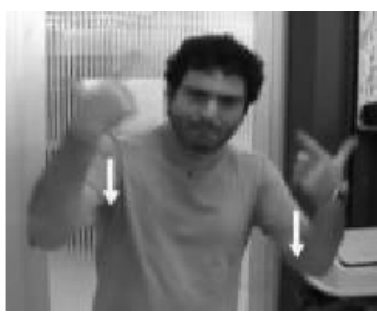

(b)

Figure 2 - Sign MORE in its citation or neutral (a) and intensified (b) forms

It is important to stress that doubling is not the only resource Libras has for expressing the intensification of the meaning of some signs. Libras can also make use of changes in other phonological parameters for the same purpose.

The intensification of the meaning of signs such as PATIENT and EXPERIENCE, for example, does not involve doubling. In addition to a change in the movement, PATIENT can undergo a change in the hand configuration and EXPERIENCE, a change in the location, as shown by Fig.3.

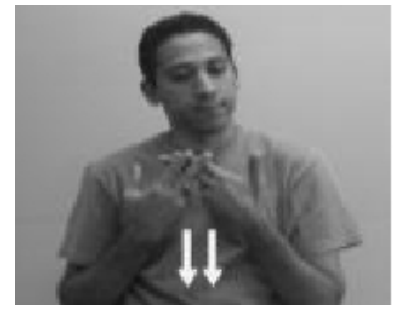

(a)

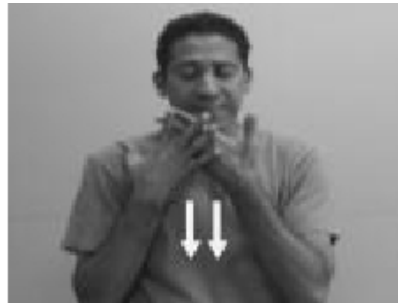

(b)

\section{PATIENT}

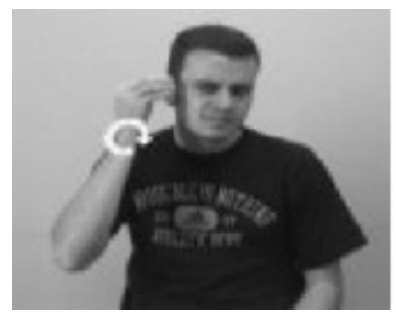

(a)

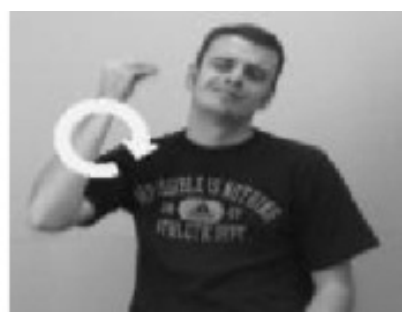

(b)

EXPERIENCE 
Figure 3 - Signs PATIENT and EXPERIENCE in both citation (a) and intensified forms (b) respectively

Although I included in the experiment (to be described in the next section) these signs and some others which seem to exhibit the same pattern, the focus of this work is on doubling. In other words, the objective of this paper is to report the results of an experiment designed and carried out (i) to elicit intensified forms of some signs of Libras and (ii) to check to what extent doubling is employed for the intensification of the meaning of some one-handed signs among the subjects of this study.

\section{Method}

\subsection{Stimuli}

The criterion for the selection of signs used as stimuli in this experiment was mainly the observation of them undergoing doubling when their meanings were being intensified in spontaneous signing. Although most of these signs (Group A below) seem to be typical one-handed signs and their observed realization with two hands seems to be the result of a process of meaning intensification, the situation is not the same for some other signs also selected for this experiment. For these signs (Group B), the number of hands with which they are produced seems to vary freely across signers. As a consequence, I expected doubling to occur in this case only with signers who adopted the one-handed variant of these signs in their citation form.

Table 1 - Groups of signs and number of signs for the experiment

\begin{tabular}{|c|c|}
\hline \multicolumn{2}{|l|}{ Group A: Typical one-handed signs } \\
\hline $\begin{array}{l}\text { ALREADY, BEAUTIFUL, DANG EROUS, DESIRE, EASY, } \\
\text { OMG, GOOD, IMPOSSIBLE, NEVER, NOT, NOT-HAVE, } \\
\text { NOT-KNOW, RELIEF, SORRY, WHAT, YES. }\end{array}$ & 16 \\
\hline \multicolumn{2}{|c|}{$\begin{array}{l}\text { Group B: Signs which vary in terms of the number of hands across } \\
\text { subjects }\end{array}$} \\
\hline $\begin{array}{l}\text { GREAT, HUNGER, INTERESTING, NEED, OK, RAIN, } \\
\text { SUFFER, SCREAM, SUMMER/HEAT, THANK-YOU, WANT. }\end{array}$ & 11 \\
\hline Total & 27 \\
\hline
\end{tabular}

I used as distractors signs whose meaning intensification does not seem to involve doubling, but a change in other phonological parameters. DESIRE was also considered a potential distractor, because it can also exhibit this pattern. Although the number of distractors shown in Table 2 is rather little (5) when compared with the number of tested signs (27), I expected that some signs of Group B would be produced with two hands in their citation/neutral form and thus become part of the distractor group, since doubling only applies to one-handed signs for obvious reasons. 
Table 2 - Distractors

\begin{tabular}{l|c|}
\hline \multicolumn{2}{|c|}{ Distractors } \\
\hline $\begin{array}{l}\text { Two-handed signs (which undergo changes in } \\
\text { handshape for meaning intensification) }\end{array}$ & \\
\hline (DESIRE), NERVOUS, PATIENT. & $2(3)$ \\
\hline $\begin{array}{l}\text { Two-handed signs (which exhibit change in location } \\
\text { for meaning intensification) }\end{array}$ & \\
\hline EXPERIENCE, PROFESSIONAL, SACRIFICE. & 3 \\
\hline Total & $\mathbf{5 ( 6 )}$ \\
\hline
\end{tabular}

\subsection{Experiment setup}

Stimuli were displayed on a laptop screen by using Microsoft Power Point in its automatic mode. The interval between each stimulus was 4 seconds and the experiment average duration was 15 minutes.

For each sign selected for this experiment, a pair of slides, one to elicit the citation form and another to prompt its intensified version, was used. Each slide of the pair featured a gloss in Portuguese and a picture illustrating or indirectly suggesting (since the meaning of most signs in the experiment is not representable through images) the sign's meaning. This methodological approach is similar to the one that has been employed by other sign language researchers $(12,13)$.

In order to make sure that the glosses would elicit the expected signs, before the beginning of the experiment, all subjects were asked to read and sign a list containing all of them. If the sign elicited by the gloss differed from the one expected, subjects were asked to think of another sign that could also be glossed with the same Portuguese word. When they managed to produce the expected sign (which always happened, even though some subjects needed more time than others), they were told to use it whenever they saw the gloss in discussion. Now, in order to prompt both the citation or neutral form of a sign as well as its intensified version, the picture featured in the slide meant to elicit the latter and to be displayed after the one prompting the neutral form suggested intensification of the meaning of the sign by exaggerating characteristics of the previous picture, as shown by Fig.4.

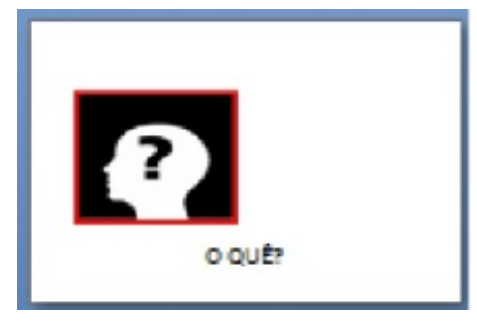

(a)

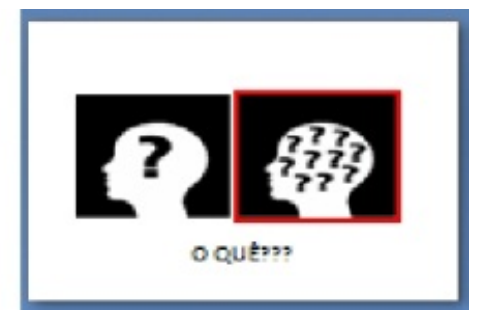

(b)

Figure 4 - Slides for eliciting the citation (a) and the intensified (b) forms of the sign O-QUÊ?(what) 
The picture (and gloss) intended to elicit the citation form was maintained on the slide meant to prompt the intensified form as a way to remind the subjects that they were supposed to intensify the meaning of the same sign the produced after seeing the previous slide and not to use a different one. All subjects were asked to look at each slide, read the gloss and examine the corresponding picture and, after that, look at another deaf person, who was sitting by the camera, and produce the sign requested by the slide to him/her.

Each pair of stimuli was presented to each subject three times in a random order. This resulted in 2,304 productions of signs ( 32 signs x 2 conditions (neutral and intensified) x 3 times x 12 subjects).

\subsection{Subjects}

The experiment was run with 6 men and 6 women, ranging from 17 to 60 years of age. All of them were born in the city of São Paulo and have lived there since then. Only two of subjects are native signers: one of them was born to deaf parents and the other has an older deaf sibling from whom she learned Libras. The other 10 subjects, for having being born to hearing parents who did not know Libras, learned it later in life (between 2 and 19 years old), mostly from deaf peers at school. All subjects reported having lots of contact with other deaf people. As for their degree of instruction and occupation, 9 of them went to university and 7 of them work as sign language instructors.

\section{Results}

All 16 signs from Group A were produced with only one hand in their citation/neutral form and most signs from Group B ( 9 of 11) exhibited the expected variation in terms of the number of hands with which they are articulated. However, as Fig. 5 below shows, these varying signs were mostly produced in their citation form with only one hand.

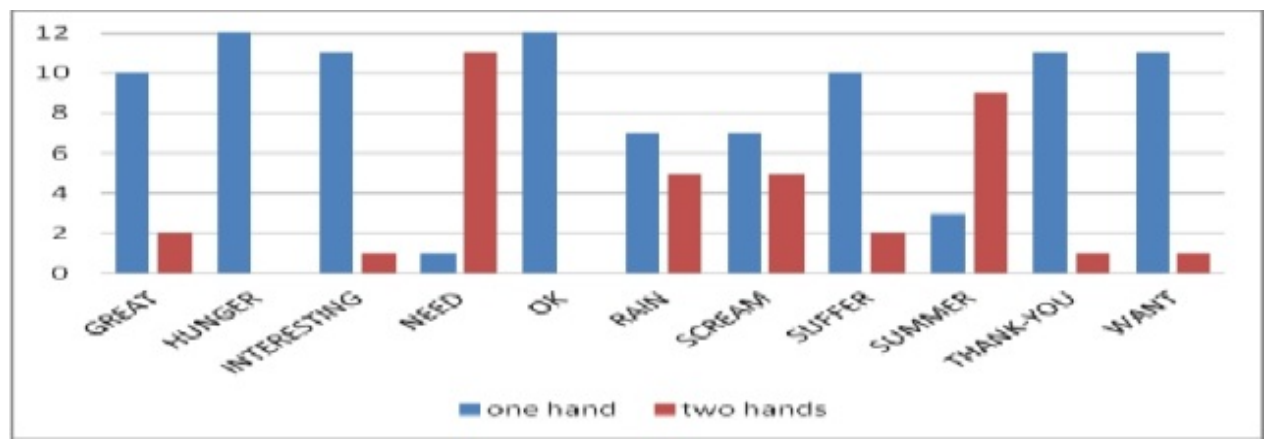

Figure 5: Number of hands in the citation form of signs of Group B 
Thus, for most subjects at least 24, out of 27 signs (Group A and B), were one-handed and, as such, could potentially undergo doubling when their meaning is intensified. Nevertheless, only 12 signs in the experiment exhibited doubling. Furthermore, these signs varied across signers in terms of frequency in which they had their number of hands doubled.

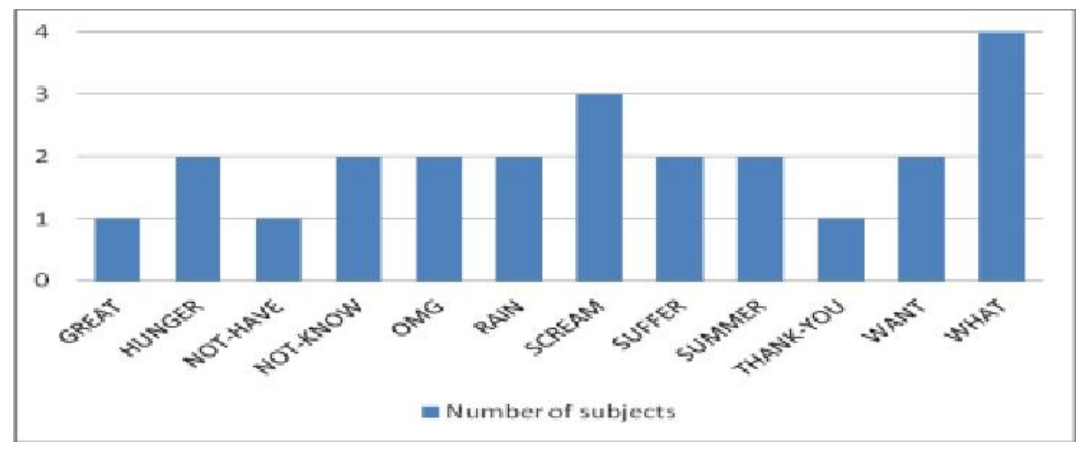

Figure 6: Frequency of doubling per sign per number of subjects

Out of 12 subjects, only 6 doubled the number of hands when intensifying the meaning of some of signs listed in Fig. 6 above. In addition, as Table 3 shows, subjects varied in terms of how many and which of the signs they doubled the number of hands for meaning intensification.

Table 3 - Signs which underwent doubling for the intensification of their meaning ( $F$ indicates a female signer, $\mathrm{M}$, a male signer)

\begin{tabular}{|c|c|c|c|c|c|c|c|}
\hline & Signs & $\begin{array}{c}\text { Subject } \\
1 \text { (F) }\end{array}$ & $\begin{array}{c}\text { Subject } \\
2 \text { (F) }\end{array}$ & $\begin{array}{c}\text { Subject } \\
3 \text { (F) }\end{array}$ & $\begin{array}{c}\text { Subject } \\
4 \text { (M) }\end{array}$ & $\begin{array}{c}\text { Subject } \\
5 \text { (M) }\end{array}$ & $\begin{array}{c}\text { Subject } \\
6 \text { (M) }\end{array}$ \\
\hline \multirow{4}{*}{$\begin{array}{c}\text { GROUP } \\
\text { A }\end{array}$} & $\begin{array}{l}\text { OMG (Oh my } \\
\text { God!) }\end{array}$ & $\bullet$ & $\bullet$ & & & & \\
\hline & NOT-HAVE & $\bullet$ & & & & & \\
\hline & NOT-KNOW & $\bullet$ & & $\bullet$ & & & \\
\hline & WHAT & $\bullet$ & $\bullet$ & $\bullet$ & & $\bullet$ & \\
\hline \multirow{8}{*}{$\begin{array}{c}\text { GROUP } \\
\text { B }\end{array}$} & GREAT & & & & $\bullet$ & & \\
\hline & HUNGER & & $\bullet$ & & & & $\bullet$ \\
\hline & RAIN & $\bullet$ & & & $\bullet$ & & \\
\hline & SUFFER & & $\bullet$ & & & & $\bullet$ \\
\hline & SCREAM & $\bullet$ & $\bullet$ & $\bullet$ & & & \\
\hline & SUMMER/HOT & $\bullet$ & & & $\bullet$ & & \\
\hline & THANK-YOU & $\bullet$ & & & & & \\
\hline & WANT & & $\bullet$ & & & $\bullet$ & \\
\hline \multicolumn{2}{|c|}{ Total } & 8 & 6 & 3 & 3 & 2 & 2 \\
\hline
\end{tabular}

One interesting fact about the results shown in Table 3 is that the two subjects who doubled the number of hands for meaning intensification the most are females. However, based on our data, this fact does not seem to be signaling a gender difference in Libras, since half of the female subjects (3) never employed doubling for meaning intensification and one of them (Subject 3) doubled the number of 
hands as much the male Subject 4.

Variation was observed to occur not only across subjects, but also within subjects. Even though most subjects who doubled the number of hands for meaning intensification exhibited a consistent behavior in the three realizations of most signs, some of them varied, by not doubling the number of hands in all three productions of the same sign in its intensified form.

Subject 2, for example, doubled the number of hands in the sign SCREAM in its first two intensified renderings, but not in its last one. Conversely, Subject 4 applied doubling for the signs GREAT, RAIN and SUMMER/HEAT only once, in their first realization, not applying the same process for the other two realizations of these signs. Subject 5, first, signed SCREAM with only one hand in both the citation and intensified forms and then, in the other two productions during the experiment, rendered both forms with two hands. The same subject was the only one to use the two-handed version of the sign DESIRE in the citation form and the one-handed version as its intensified form. However, it is noteworthy that when producing the citation form of DESIRE, Subject 5 first signed it with two hands and right after with only one hand in two of three renderings of this sign in that form.

As for the articulatory properties of the signs that underwent doubling, the analysis of the data obtained showed that in these cases the nondominant hand virtually copies/mirrors the features and activities of the dominant hand. Specifically, the nondominant hand in the intensified forms of GREAT, HUNGER, NOT-HAVE, NOT-KNOW, OMG (as produced by Subject 2), RAIN, SCREAM, SUFFER, SUMMER/HEAT, THANK-YOU, WANT and WHAT (as produced by Subject 1), besides exhibiting the same handshape as the dominant hand and mirroring its orientation and location, moves simultaneously to it, as suggested by Fig.7.

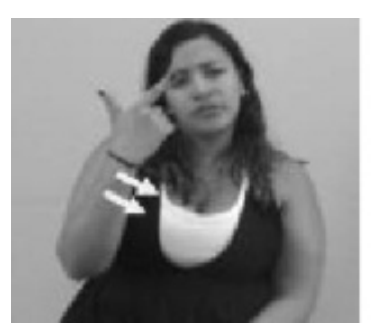

(a)

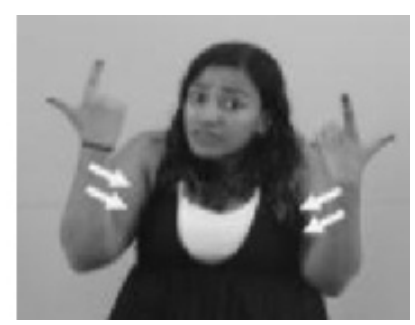

(b)

Figure 7 - Sign NOT-HAVE in its citation form (a) and in its intensified form as produced by Subject 1

An exception to this pattern was observed in the production of the sign WHAT and OMG. 3 of the 4 subjects who doubled the number of hands when intensifying WHAT employed an alternating circular movement instead of a simultaneous one. The same phenomenon was observed with the sign OMG, which was produced with an alternating movement by Subject 1, when expressing an intensification of its meaning. 
For some signs, doubling was accompanied by other changes in other phonological aspects of the sign. In HUNGER (Fig.8), for example, Subject 2 not only doubled the number of hands when intensifying the meaning of this sign, but also changed its palm orientation.

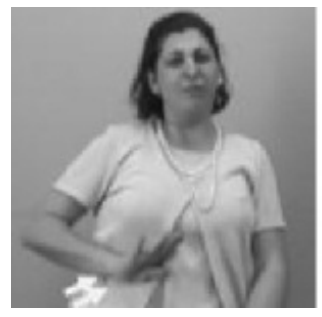

(a)

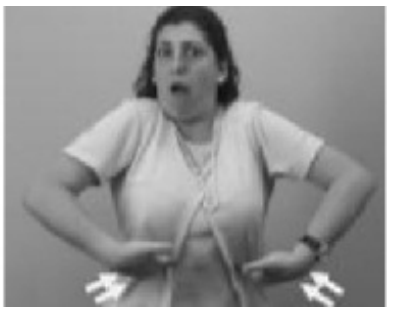

(b)

\section{HUNGER}

Figure 8 - Sign HUNGER in both citation (a) and intensified forms (b) respectively, as produced by Subject 2

A two-proportion z-test $(\alpha=0,05)$ was performed for each subject using R. To do this test, I took into account only the productions of the twelve signs that underwent doubling in the experiment. Since these signs were produced in two different conditions and repeated three times $(12 \times 3 \times 2)$, the total of productions for each signer I considered was 72 . However, because of some stimuli were misproduced, some renditions had to be discarded, thus lowering the total of productions of some subjects.

Table 4 - Result of the two-proportion z-test per subject

\begin{tabular}{|c|c|c|}
\hline Subjects & Total of productions & 2 hands / 1 hand \\
\hline 1 & 72 & $23 / 49^{*}$ \\
\hline 2 & 69 & $17 / 52^{*}$ \\
\hline 3 & 72 & $8 / 64^{*}$ \\
\hline 4 & 72 & $3 / 69^{*}$ \\
\hline 5 & 69 & $5 / 64^{*}$ \\
\hline 6 & 66 & $6 / 60^{*}$ \\
\hline
\end{tabular}

As Table 4 shows, there is a significant difference between the proportion of signs produced with one and two hands. This result confirms the descriptive statistics which had signaled that among the subjects who employed doubling for meaning intensification most of them seem not to do so as frequently as Subjects 1 and 2 .

Although doubling can be regarded as a resource for the expression of meaning intensification in Libras, the data obtained through this experiment suggested that it seems to be optional not only among signers but also, in some cases, within the same signer.

The same seems to hold true for the use of changes in the parameters hand configuration and 
location to express meaning intensification. Out of the 12 subjects, only a few changed the handshape of the sign DESIRE, PATIENT and NERVOUS ( 2 for the former and 1 for the latter) and the location of EXPERIENCE and SACRIFICE ( 3 for the former and 4 for the latter).

Table 5 - Signs which can exhibit change in other phonological parameters in their intensified forms per number of subjects

\begin{tabular}{|c|c|c|c|}
\hline Group & Signs & $\begin{array}{c}\text { Hand } \\
\text { Configuration } \\
\text { change }\end{array}$ & $\begin{array}{l}\text { Location } \\
\text { change }\end{array}$ \\
\hline \multirow{3}{*}{ c } & DESIRE & 2 & \\
\hline & NERVOUS & 1 & \\
\hline & PATIENT & 2 & \\
\hline \multirow{3}{*}{$\mathbf{D}$} & EXPERIENCE & & 3 \\
\hline & PROFESSIONAL & - & - \\
\hline & SACRIFICE & & 4 \\
\hline
\end{tabular}

An interesting fact about the intensification of the meaning of the sign SACRIFICE is that for Subjects 2 and 3 it was always accompanied by a change in hand configuration: they extended their pinky. Even though in other subjects the extension or not of the pinky finger seemed to be a matter of individual variation, Subjects 2 and 3 consistently employed the pinky extension only when they produced the intensified form of SACRIFICE (Fig.9).

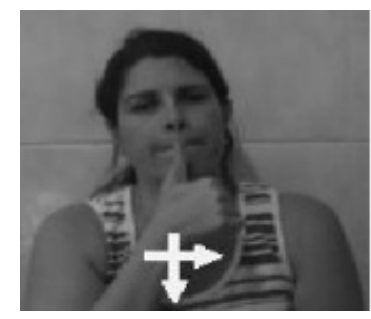

(a)

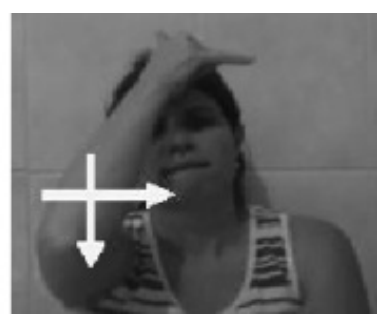

(b)

Figure 9: Sign SACRIFICE in its citation form (a) and in its intensified form as produced by Subject 3

\section{Conclusion}

The results of the experiment reported here show that even though Libras users can employ the doubling of the number of hands to express the intensification of the meaning of some signs, this resource does not seem to be used as frequently as expected. This fact seems to be consistent with the use of changes in hand configuration and location for the same purpose, since just a few of the participants of this study used them when producing the intensified form of some signs. 
Despite the apparent optionality of doubling and changes in hand configuration and location for the expression of meaning intensification in Libras, however all 12 subjects were very consistent in using changes in their facial and body expressions as well as in the characteristics of the movement (size, speed, tenseness) of their hands when expressing intensification of the meaning of a sign. This fact not only evidences that subjects understood the experiment task (precluding the possibility that the tested phenomenon did not happen as much because of the subjects' lack of understanding of what they were expected to do), but also signals the obligatory character of changes in face and body expressions and hands' movements when expressing meaning intensification.

This study also revealed the occurrence of intra and inter-subject variation in Libras users. Even though most subjects behaved in a very consistent way by doubling or not the number of hands of typical one-handed signs when producing their intensified forms, a few of them varied by realizing this form sometimes with one hand, sometimes with both. As far the inter-subject variation, the analysis of the data obtained through the experiment discussed here showed that subjects can in two different ways. They can vary not only in terms of applying doubling for the intensification of the meaning of more or fewer signs, but also in relation to applying the same process to signs that are different from the ones which have their number of hands doubled for the same purpose by other signers.

\section{Acknowledgments}

I wish to thank our 12 subjects for taking part in our experiment and giving us permission to use their image to illustrate the data we have obtained. We also wish to thank the National Federation for the Education and Integration of the Deaf (FENEIS) in São Paulo for allowing us to use their studio. At last, we thank the National Council for Scientific and Technological Development (CNPq) for providing the grant for this research (151395/2010-1).

\section{REFERENCES}

1. Stokoe, W. C. Sign language structure. Silver Spring, MD: Linstok Press, 1960.

2. Battison, R. Phonological deletion in American Sign Language. Sign Language Studies, 5, 1-19, 1974.

3. Klima, E. and Bellugi, U. The signs of language. Cambridge, MA: Harvard University Press, 1979.

4. Xavier, A. N. Descrição fonético-fonológica da língua de sinais brasileira. Master's dissertation, 2006.

5. Capovilla, F. C and Raphael, W. Dicionário ilustrado trinlíngue da língua brasileira de sinais. Edusp, 2001.

6. Xavier, A. N. Variação fonológica na libras: um estudo da alternância no número de articuladores manuais envolvidos na produção dos sinais. In: XVII SETA - Seminários de Teses em Andamento, 2011, Campinas. Anais do SETA, v. 5. 119-145, 2011.

7. Xavier, André Nogueira. Com uma ou duas? Com duas ou uma? A alternância no número de mãos 
envolvidas na produção de sinais da libras como fenômeno coarticulatório. In: XVII SETA (Seminários de Tese em Andamento), 2012, Campinas. Anais do SETA, v. 6. p. 29-43.

8. Woodwar, J. Two-to-One It Happens: Dynamic Phonology in Two Sign Languages, Sign Language Studies, 17 (1977:Winter) p.329. v. 17, 1977.

9. Padden, C. A.; Perlmutter, D. American Sign Language and the Architecture of Phonological Theory, Natural Language and Linguistic Theory, 5:3 (1987:Aug.) p.335. v. 3, 1987.

10. Johnson, R.; Liddell, S. K. American Sign Language: The phonological base. Sign Language Studies, v. 64, 1989.

11. Johnston, T.; Schembri, A. On defining lexeme in a signed language. Sign Language and Linguistics, 2(2), 115-185. 1999.

12. Sandler, W. Phonological category resolution: A study of handshapes in younger and older sign languages. In: Channon, R; Hulst, H. (Eds.). Formational Units in Sign Language. Ishara Press, 2010.

13. Tyrone, M. et al. Prosody and Movement in American Sign Language: A Task-Dynamics Approach. Speech Prosody 2010. 